\title{
EDITORIAL
}

\section{The First International Conference on Translational Medicine}

\author{
Molecular Psychiatry (2010) 15, 878-879; doi:10.1038/ \\ mp.2010.91
}

As our mission to foster translational medicine continues to evolve, we have now conceptualized and launched a new international conference to cover the transition from discovery to healthcare and global health. The First International Conference on Translational Medicine (the 13th Frank and Bobbie Fenner Conference) has a highly innovative mission of bringing together into a global domain what have so far been nationally focused efforts in translational medicine, such as the United States Clinical and Translational Science Award (CTSA) mechanism and the United Kingdom Academic Health Science Centre (AHSC) program. Initiatives from Ireland, which created one academic health science center for the entire country, from China, Singapore and Australia will also be discussed and presented (see Table 1).

While carefully thought out and well-funded programs have been developed in many countries to foster translational medicine, the vast majority of those efforts are funded by national taxpayers' sources and are therefore restricted for use within each country. What is currently lacking in the world is an international structure that integrates various national translational efforts, promotes cross-fertilization, thereby avoiding duplication of effort, and that brings the fruits of research to those who are less privileged, through global health initiatives. By bringing together a very elite group of academic leaders in translational medicine, we will start an organized process to address these pressing issues.

The discussion of whether the outcomes of translational research will be restricted to rich, industrial and post-industrial countries with an economic basis to nurture national efforts in translation is of considerable importance. That being the case, what happens to countries that cannot support such efforts? The premise of translation is to improve health, and if that is being done only in wealthy countries, will translational medicine become a lever to further raise the rich, while the poor stay behind? Are we simply expanding the abyss in health outcomes that exist between disadvantaged nations and traditionally (or rapidly emerging) rich countries? If that is not the desired outcome, how can translational medicine be brought to the poor, whose health needs are so profound? How will translational research on neglected tropical diseases or on illnesses that have long ceased to be public health problems in developed countries be funded? Who will develop
Table 1 First International Conference on Translational Medicine (The 13th Frank and Bobbie Fenner Conference), 1-4 November 2010, John Curtin School of Medical Research, ANU, Canberra, Australia

Participant leaders from the USA, Europe, China,

Singapore and Australia:

Warwick Anderson, CEO, NHMRC, Australia

Juan Carlos Lopez, Chief Editor, Nature Medicine

Anthony Hayward, Director, Clinical and Translational

Program, NIH, USA

Alan Schechter, Chief, Molecular Medicine, NIDDK,

NIH, USA

Clay Johnston, Director, UCSF Clinical and Translational Science Institute

Anantha Shekhar, Director, Indiana Translational

Institute, USA

Dame Sally Davies, Director General of Research and Development and Chief Scientific Adviser for the Department of Health and NHS, London, UK

Alastair Buchan, Head, Medical Sciences Division (Dean of Medicine), University of Oxford, UK

Stephen Smith, Dean of Medicine and CEO, Imperial College Healthcare and AHSC

Bill Powderly, Dean of Medicine, CEO, Dublin Academic Medical Centre

Jun Wang, Executive Director, BGI-China

Lin He, Director, Bio-X Center, Shanghai Jiao Tong

University and Dean, Institutes of Biomedical Sciences,

Fudan University, Shanghai, China

Ranga Krishnan, Dean, Duke-NUS Medical School,

Singapore

Alain van Gool, Director, Translational Medicine

Research Centre, Merck Singapore

Eran Leitersdorf, Dean, Faculty of Medicine, Hebrew

University of Jerusalem, Israel

Sir Gustav Nossal, AC, CBE, FAA, FRS

Bruce Singh, Acting Dean, University of Melbourne

Steve Wesselingh, Dean of the Faculty of Medicine,

Monash University

Bruce Robinson, Dean, University of Sydney School of Medicine

Conference website: http://bit.ly/clopnZ.

translational approaches to the diseases that cause so much morbidity and mortality the world over?

Of course, translational medicine is fundamental for chronic, non-transmissable illnesses. However, the diseases of the rich are to a large degree the outcome of affluence. If we eliminated overeating, underspending of calories due to sedentary lifestyles, drugs, alcohol and cigarette smoking, health in developed countries would be greatly improved, without any translational medicine. 
Translational strategies that go from bench to bedside to clinic to health policy are sorely needed to address malaria, tuberculosis, leprosy, Chagas and diarrheal diseases, among others. The case could be made that the public health relevance of those diseases would be greatly reduced by improved social and economic standards. That is true; however, it is not fair to let hundreds of millions die around the world over the coming decades as we sit and wait for the quality of life to incrementally rise across the globe. In parallel to promoting better standards of living, we need to bring translational approaches to address not only the diseases of the rich, but also the diseases of the poor. Are these efforts the responsibility of international bodies, such as the World Health Organization, or are they best funded by non-governmental organizations, such as the Bill \& Melinda Gates Foundation? Should national translational programs in the developed countries dedicate a percentage of their budgets to initiatives that are of more direct benefit to poorer nations? What is the role of rapidly emerging countries?

These difficult questions will only become more pressing over time and will be a major challenge for the translational research leaders of the future. Are we effectively developing in sufficient numbers a global workforce in translational medicine? How do we train academic leaders who can direct the multidisciplinary translational research teams of the future? They will have to simultaneously understand in depth and navigate the worlds of discovery and healthcare, survive and thrive tough peer review, and will moreover need to acquire extraordinary skills not only in the multidisciplinary science and practice of medicine, but also in the communication of science, fund raising, management, advocacy and community engagement. How can those future leaders be identified, nurtured and transitioned into the right positions at the optimal time in their careers?

Finally, a very clear-minded dialogue must exist to estimate the proportion of funding that goes into fundamental discovery, versus what goes into building the infrastructure and pipeline of translation. Both are equally needed and healthcare and global health cannot be improved by one without the other.

These three very hot topics will be approached in a moderated discussion or workshop format:

- How to Create Academic Structures and Partnerships that Integrate Fundamental Discovery, Translational Medicine, Health Care and Global Health. Moderated open discussion led by Robert Wells (Australian Primary Health Care Research Institute and Menzies Centre for Health Policy, ANU).

- Developing a Global Translational Research Workforce. Workshop led by Michele Pato (University of Southern California), Monika Ehrhart-Bornstein (University of Dresden, Germany) and Julio Licinio (John Curtin School of Medical Research, ANU).

- Where Should the Money Go? To Fundamental Discovery or Translation? Moderated open discussion led by Eran Leitersdorf (Dean, Faculty of Medicine, Hebrew University of Jerusalem, Israel), Anthony Hayward (Director, Division of Clinical Research Resources, NCRR, NIH), Warwick Anderson (CEO, NHMRC), Alastair Buchan (Dean of Medicine, University of Oxford, UK), and Julio Licinio (Director, JCSMR, ANU).

We invite you and your colleagues to come to beautiful Canberra on 1-4 November 2010 to attend this transformative conference that will for the first time bring into one venue some of the most competitive initiatives in translational medicine worldwide. We also invite you to submit to our poster session. I am looking forward to welcoming you to Australia.

J Licinio (Editor)
John Curtin School of Medical Research,
Australian National University, Canberra, Australia
E-mail: Julio.Licinio@anu.edu.au
E-mail: Julio.Licinio@anu.edu.au 